\title{
The Effects of Job Stress and Hope on the Happiness of Office Workers: The Moderated Mediation Model of Growth Mindset
}

\author{
Chang Seek Lee, Ji Young Park
}

\begin{abstract}
The study was to verify the moderated mediation effect of growth mindset on the relationship between stress and happiness through hope for 338 office workers in Korea.

SPSS Win. 21.0 were used to analyze the reliability, descriptive statistics, and correlation analysis in this study. The moderated mediation effect of growth mindset was analyzed by applying SPSS PROCESS macro Model 7. To verify the moderated mediation effect, the bootstrap analysis was set to 5,000 iterations, and the confidence interval was set to $95 \%$.

Research findings are as follows. First, job stress had negative correlation with hopes, growth mindset and happiness. Happiness had positive correlation with hopes and growth mindset. Second, the growth mindset moderated the relationship between job stress and happiness via the hope of office workers, which verified the conditional indirect effect of job stress on happiness.

These results will help increase office worker's happiness through hope and growth mindset.
\end{abstract}

Keywords : Job stress, Hope, Happiness, Growth mindset, Moderated mediation model

\section{INTRODUCTION}

$\mathrm{H}_{\text {appiness is the greatest goal that human beings seek in }}$ their daily life situation. This happiness is defined as an overall assessment of the quality of one's life based on the criteria he or she chooses as an overall, integrated judgment of all aspects of life [1]. In addition, happiness is defined as a relatively continuous feeling of well-being, not a mere emotion or mood, due to the perception of the cognitive and emotional evaluation of one's life, and defined as the degree to which a person positively judged the quality of his or her life $[2,3]$. Various variables influence this happiness as experience in an individual. Among them, job stress is a factor affecting the happiness of the worker in the workplace, and can affect whether the worker has stressors on the job in the workplace environment.

Job stress is defined as a condition in which an individual's and the job environment of the organization and individual desires are inadequate [4]. Job stress is a harmful physical and emotional response that occurs when job requirements are inconsistent with workers capabilities, resources, and needs [5]. Therefore, whether the job demands exceed the

Revised Manuscript Received on July 22, 2019.

Chang Seek Lee, Dept. of Health, Counseling and Welfare, Hanseo University, 31962, Republic of Korea. Email: lee1246@ hanmail.net

Ji Young Park, Dept. of Child and Elderly Welfare, Koguryeo University, 58280, Republic of Korea. . Email: jteddy@naver.com skills and abilities are inadequate to the job's specifications,

individual's response capacity or the individual's response ability exceeds the job requirement, the unbalance as shown between the two factors can result in the experience of stress [6]. In addition, it has been reported that job stress may have a negative impact on organizational effectiveness such as job satisfaction and organizational commitment [7], and heavy work experiences also had negative consequences on the individual, such as lowering job performance, increasing emotional exhaustion and psychological tensions [8, 9]. For this reason, job stress has been researched steadily to find strategies to alleviate stressor for workers in all industries in the workplace environment.

On the other hand, scholars categorize job stress by various criteria in order to clarify and identify job stressors. Cooper and Marshall [10] defined job stress as a negative environmental factor related to job, and included factors such as job overload, role ambiguity, role conflict, and poor working conditions as reasons for job stress. In addition, Gupta and Beehr [11] categorized job stressors into job demands, task characteristics, role demands and role expectations, organizational characteristics and situations, internal needs and situations. And Schuler [12] suggested such stress factors as characteristics of the job and its stressors, interpersonal relationship, organizational structure, leader process, and the physical condition of the individual experiencing the job stress. In addition, Parker and Decotiis [13] categorized job stresses more specifically: job self (autonomy, identity diversity), organizational characteristics (organizational structure, organizational atmosphere), organizational roles (role ambiguity, role conflict, role overload), career development (promotion performance development), and interpersonal relationship (relationship with supervisor, colleagues, and subordinates). Therefore, the causes of job stress are diverse and there are many disagreements among conventional scholars, and thus systematic research is needed to bring light to this issue to find resolutions to these problems experienced by workers on the low end of happiness levels researched.

Job stress was closely related to happiness as seen in previous studies. In a study of social workers, job stress had a negative effect on the level of happiness experienced by these workers [14]. In the study of early childhood teachers, the higher the job stress, the lower the happiness and the negative influence on those workers [15]. 
In addition, the job stress of elementary school teachers [16], local public servants [17] and infant teachers [18] had a negative effect on their level of experienced happiness and life satisfaction. In this way, job stress has been found to have a negative effect on human happiness, and it is necessary to find ways to improve happiness through the discovery and intervention of variables that play a buffer role in the relationship between these two variables to offer interventions to increase happiness levels among workers. Among these variables, hope and growth mindset have recently been discussed at domestic and abroad as relevant factors to improving happiness levels of the workers.

First, hope was initially defined as a positive expectation for goal acquisition [19, 20]. This hope began to be systematically studied by Snyder et al. [21], who defined hopes as a positive motivational state that showed an example of how pathways thinking and agency thinking are interactively organized in an individual's brain [22]. And the components of hope are, first, to have and to develop practical goals. Second, the search for pathways thinking is important to be considered as a practical way of achieving the goal. Third, having an agency thinking that is a motive for steadily implementing these methods is an important factor to review in these cases [23].

Those individuals with high hopes were challenging, focusing on success rather than failure, more likely to achieve goals, and maintaining a positive emotional state. On the other hand, those individuals with low hopes do not do their best, focus on failure, focus on the possibility of failure, and maintain a negative emotional state [24]. In addition, people with high hopes tend to have difficulties in our lives such as in the event of a disability, while those with low hopes tend to perceive such difficulties to happen only to one-self. In addition, people with high hopes tend to think of social support networks and actively ask for help from others when they have to solve difficult problems, but those with low hopes tend not to have social support networks to help them manage stressors, and tend not to seek social support. Moreover, those with low hopes are less flexible in their use of pathways to pursue goals, experience negative emotions when they focus on only the original initial goal, are immature in using or developing alternative strategies, and often for this reason fail to achieve goals [25]. Thus, hope is a positive trait that has important implications for individuals and society to set and realize better goals [26].

Hope, on the other hand, has been identified as a factor that cushions or mitigates stress. In the face of stress during goal pursuits, those individuals with high hopes perceive themselves as being able to overcome stress by finding alternative ways to resolve life's problems [22]. Indeed, those individuals with high hopes came up with more alternatives than those with low hopes to manage issues, and responded more aggressively to stress in a way to alleviate the stress in their lives. In addition, high hopes were reported to adjust to cope with unpredictable stressors [27]. When faced with stressors, high-hopes people create more strategies to deal with stressors than lower hope people (pathways thinking), and showed a tendency to use these strategies more (agency thinking) $[22,24,25]$. Furthermore, those with high hopes

had a rapid recovery of the stress response in situations that would have routinely created stressors [28].

This hope has been found in many studies as a mediator for this experience by the individual. In the study of female marriage immigrants in Korea, hopes were found to be mediating roles in the relationship between family related stress of immigrants and well-being of the person being studied [29], and stress coping and psychological well-being of the female marriage immigrants [30]. In a study of mothers with children attending kindergarten, hope mediated in the relationship between growth mindset and child well-being, and parental stress and child well-being [31]. In addition, hope in the study of university students partly mediated in the relationship between attachment and mental health in that case [32]. In this vein, it is necessary to verify whether hope mediates in the relationship between job stress and happiness of employees and office workers.

On the other hand, mindset is referred to as a frame or lens of the mind that interprets and selectively organizes information [33]. In this way, mindset is formed in the process of developing people's beliefs that organize the world in their own way, such as organizing how they perceive the world and gives meaning to their experiences. Therefore, mindset is not the same for every person, because each individual will create different psychological worlds according to their own beliefs, and therefore think, feel and act differently if viewed in the same situation [34].

This mindset is divided into the two categories of growth mindset and fixed mindset. Growth mindset is a belief that experience and effort can improve talent and intelligence, while fixed mindset is a belief that the ability is fixed and cannot be changed [33]. A person with a growth mindset believes that intelligence can be developed and improved in an individual, and that the human brain is like a muscle that can be improved through training. This stimulates desire for a change in the individual [35]. On the other hand, a person with a fixed mindset believes that intelligence has inherent characteristics, and therefore believes that there is a certain amount of thinking on this topic. For example, students with a growth mindset try hard with innovative strategies and high continuity, but students with a fixed mindset have a negative response to the challenge, lack of patience, and maladaptive coping behaviors and helpless reactions, such as a desire to quit the task before it is completed [36, 37].

In this instance, growth mindset is a belief that intelligence can be changed through effort and learning. It is applied not only to intelligence but also to various fields such as academic achievement, aggression in personality, consciousness, and is seen in the development of human relationships. The degree of stress coping depends on the application of the mindset. In other words, Crum et al. [38] found that people with a "mindset" of "stress is beneficial" had a moderate level of cortisol hormone secretion as was identified in stress situations. For people with low cortisol responses, the mindset that "stress is beneficial" promotes cortisol secretion, and for those who have a high cortisol response, this "mindset" mitigates a cortisol secretion [38]. 
Therefore, growth mindset, which perceives that stress is beneficial, has positive results in terms of work performance and physical health than in the identified fixed mindset of individuals who perceive that stress is harmful. Based on the results of previous studies, the level of stress will vary according to whether workers have a growth mindset or fixed mindset in coping with their experiences of job stress, and the level of happiness will change accordingly. Therefore, it is necessary to verify when growth mindset intervenes in the relationship between job stress and happiness.

In addition, previous studies have shown that growth mindset moderates the relationship between adult leadership and organizational effectiveness [39, 40], and can affect or influence the relationship between adult hope and an organizational effectiveness of the employees at a company [39]. It is also reported that hope moderated the relationship between self-esteem of middle school students, and may have an effect on the experiences of school violence as experienced by the students enrolled at schools at that level [41]. In addition, in a study for adults, growth mindset showed moderated mediation effect in the path of authentic leadership, hope and organizational effectiveness [39]. In this respect, the growth mindset of middle school students moderated the path from parental abuse to school violence via self-esteem [41]. Therefore, it is necessary to verify whether growth mindset moderates the path of job stress, hope, and happiness in order to find strategies to use to enhance the happiness of the workers.

On the other hand, workers are experiencing various difficulties compared with other age groups, and among them, job stress is reported to be the most serious problem experienced by workers on the job. That being said, it is seen that $87.8 \%$ of workers are experiencing abnormalities which may be linked to job stressors, such as lethargy and digestive diseases due to job stress, and $74.4 \%$ experience depression while employees of various companies in Korea [42]. In addition, in 2009, job stress felt by Korean workers was at the highest levels, and it was subsequently noted that these workers had the lowest level of job satisfaction among OECD member countries. In a study on the stressors plagued by individuals of large firms, it was found that stressful factors such as heavy work, working environment, promotion, lack of ability, achievement of goal, future anxiety and simple task were important stress factors that affect the employees and workers [43]. In a stress study of central government officials, the excess of workload has a significant and direct impact on job stress, as well as negatively affecting organizational commitment, job commitment, and job satisfaction of the workers in the workplace environment [44]. Therefore, it is necessary to plan ways to mitigate job stress for the workers, which can help to raise their level of satisfaction with the job and raise their perception of hope in relation to their work environment. In particular, it is necessary to study the various complex pathways from job stress to happiness through hope and growth mindset variables, which are emerging positive psychological variables inherent in individuals to some varying degree (as studied here), and to find ways to solve the problem of job stress based on these results.

Therefore, the purpose of this study is to find out the moderated mediation effect of growth mindset on job stress and hope affecting happiness, and to improve the happiness of the worker who is suffering from job stress in the workplace environment. In order to achieve these research objectives, the following research questions were created for review. Two major questions need to be asked at the outset of this research: First, what is the correlation between job stress, hope, growth mindset, and happiness? Second, does growth mindset moderate the mediating effect of hope in the relationship between job stress on happiness?

\section{RESEARCH METHOD}

\section{A. Research model}

Based on the previous researches, the research model that was used categorized job stress shown where it directly affects happiness, hope mediates this direct effect, and this mediation is moderated by growth mindset, was set as shown in Figure 1.

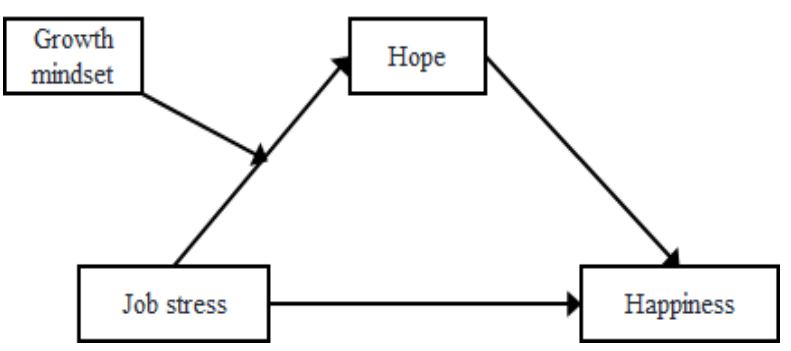

Figure 1: Research model

\section{B. Research subjects and data collection methods}

For the subjects of this study individual participants from 3 cities and counties in Chungcheongnam-do, Korea were randomly sampled, and 338 workers including civil servants, business workers, and social welfare workers were purposively sampled. Data were collected through questionnaires that were sent to the participants and returned for review to the researchers. The data were collected in consideration of the sex ratio, the position ratio, and the occupation rate.

\section{Research tools}

\section{Job stress}

In this study, we used the scale developed by Parker and DeCotiis [13] to measure the amount of job stress experienced by a participant. This scale was developed to assess overall job stress on a regular basis, with a focus on the signs and inclinations manifesting in the individual as precursors of job stress. A total of 13 items are rated on a 5-point Likert scale from " $1=$ absolutely untrue" to " $5=$ absolutely true." The higher the score, the higher the job stress as noted in the individual. In this study, the Cronbach alpha for job stress was .830 .

\section{Hope}

To measure hope, we use the Korean version of the hope scale (K-DHS), which is adapted and validated by Choi et al. [45]. It was originally developed by Snyder et al. [21]. 
In this case, hope is composed of four items of agency thinking that measure goal setting, and four items of pathways thinking that measures how to reach the goal. A total of 8 items are rated on a 5 -point Likert scale from " $1=$ absolutely untrue" to " $5=$ absolutely true." The higher the score, the higher the level of hope as measured in the individual studied. In this study, the Cronbach alpha for hope was .903.

\section{Growth mindset}

Growth mindset scale is a tool utilized for measuring how close an individual is to a fixed mindset or growth mindset. We used the growth mindset scale which was developed by Dweck [33], which is divided into subgroups of intelligence and personality. A total of 8 items are rated on a 5-point Likert scale from " $1=$ not at all" to " $5=$ very agree." The higher the total score, the higher the growth mindset as noted in the individual studied. In this study, the Cronbach alpha for growth mindset was 797 .

\section{Happiness}

To measure a happiness factor, we used the happiness scale which was developed by Lyubomirsky and Lepper [46], and used by Shin[47] (2012). The scale consists of 5 items and each item consists of a 5-point Likert scale from " $1=$ not at all" to " $5=$ very agree." The higher the score, the higher the identified measure of happiness of the subject. In this study, the Cronbach alpha for growth mindset was .872 .

\section{Data Analysis}

In this study, SPSS Win. 23.0 and SPSS PROCESS macro ver. 3.2 were used for determining the statistical analysis. First, SPSS Win. 23.0 was used for identifying the descriptive statistics, reliability analysis, and correlation analysis of the variables. Second, SPSS PROCESS macro ver. 3.2 was used for the moderated mediation effect analysis. And in this case, for the verification of effect analysis we used a bootstrap method, in which the number of bootstrap samples was set to 5,000 , and the confidence interval was set to $95 \%$.

\section{RESULTS AND DISCUSSION}

\section{A. Correlation analysis and Descriptive statistics}

The correlation analysis was performed to determine the relationship between the reviewed variables. The results are shown in Table 1. As a result of analysis, job stress had negative correlation with hope, growth mindset and happiness. And in this reference, there was a positive correlation between happiness, hope and growth mindset. Among these variables studied, happiness and hope had the highest correlation coefficient $(r=.574, \mathrm{p}<.01)$.

Descriptive statistics analysis showed that the mean of happiness was higher than the mean of hope and growth mindset, and the mean of the job stress was lower than the median score ( 3 points).

Table 1: Analysis of correlation and descriptive statistics among the main variables

\begin{tabular}{|c|c|c|c|c|c|}
\hline & 1 & 2 & 3 & $\mathrm{M}$ & $\mathrm{SD}$ \\
\hline $\begin{array}{l}\text { 1. Job } \\
\text { stress }\end{array}$ & 1 & & & 2.6354 & 0.61527 \\
\hline
\end{tabular}

\begin{tabular}{|c|c|c|c|c|c|}
\hline 2. Hope & $-0.251^{*}$ & 1 & & 3.5564 & 0.59465 \\
\hline $\begin{array}{c}\text { 3. Growth } \\
\text { mindset }\end{array}$ & $-0.245^{*}$ & $0.257^{* *}$ & 1 & 3.3335 & 0.61394 \\
\hline $\begin{array}{c}4 . \\
\text { Happiness }\end{array}$ & $-0.359^{*}$ & $0.574^{* *}$ & $0.295^{* *}$ & 3.7139 & 0.65985 \\
\hline
\end{tabular}

\section{B. The moderated mediation effect of growth mindset}

Table 2 and Figure 2 shows the moderated mediation effects of the growth mindset. An analysis was made using an analysis procedure of a Model 7 by using the SPSS Process macro. First, the moderating effect of the growth mindset was shown to be verified, because the interaction term between job stress and growth mindset was significant $(-.1509, \mathrm{p}<.05)$. In addition, the test value of R2 was significant (.0104, $\mathrm{p}<.05$ ), and thus the moderating effect of the growth mindset was also subsequently verified. The moderating effect of growth mindset was consistent with similar previous studies[39-41].

The conditional effects of independent variable, job stress, were measured on the M-SD, M, and M+SD values of the growth mindset. As a result, the known conditional effects of the job stress at $M$ and $M+S D$ values of growth mindset was significant. Namely, the growth mindset was effective in the middle and high level of the growth mindset.

As the results of analyzing the conditional effects of the job stress at values of growth mindset by using the Johnson-Neyman significance region, the moderating effect of growth mindset was shown to be not significant when the growth mindset value was lower than -.5198 , but when the growth mindset was higher than -.5198 , the moderating effect of growth mindset was shown to be considered significant. In addition, the number of subjects who belonged to a region with a growth mindset value lower than -.5198 was $16.86 \%$, and the number of subjects who belonged to a region with a growth mindset value higher than -.5198 was $83.16 \%$.

When job stress decreased, hope decreased, but this decrease was more apparent in the lower group of growth mindset than in the higher group as was studied.

On the other hand, if the influence of the independent variable on the mediating variable is significant, and the effect of the mediating variable on the dependent variable is significant, the mediating variable is considered to be a mediating effect[48]. Therefore, job stress had a significant effect on hope $(-.2024, \mathrm{p}<.001)$, and hope had a significant effect on happiness $(.5741, \mathrm{p}<.001)$. Therefore, it was verified that hope mediated in the relationship between job stress and happiness for the employees studied. The mediating effects of hope were in line with the results of similar studies as seen in a review of the literature on this topic $[29,30,32,41]$.

The conditional indirect effect of job stress on employee happiness was shown to be statistically significant at the $\mathrm{M}$ and $\mathrm{M}+\mathrm{SD}$ value of growth mindset, and thus the growth mindset moderated the path of job stress $\rightarrow$ hope $\rightarrow$ happiness at medium and higher level of growth mindset, which verified the moderated medication effect of growth mindset. 
Therefore, when the growth mindset is at the M or M+SD values, the path of job stress $\rightarrow$ hope $\rightarrow$ happiness was considered to be buffered.

Table 2: Analysis of moderated mediation effect of growth mindset

\begin{tabular}{|c|c|c|c|c|c|c|}
\hline Variables & Coeffect & SE & t-value & $p$ & $\mathrm{LLCI}^{*}$ & $\mathrm{ULCI}^{* *}$ \\
\hline \multicolumn{7}{|c|}{ Mediating variable model(DV: Hope) } \\
\hline constant & 3.5469 & .0314 & 112.9469 & .0000 & 3.4851 & 3.6087 \\
\hline Job stress & -.2024 & .0516 & -3.9243 & .0001 & -.3038 & -.1009 \\
\hline $\begin{array}{l}\text { Growth } \\
\text { mindset }\end{array}$ & .1741 & .0525 & 3.3187 & .0010 & .0709 & .2773 \\
\hline $\begin{array}{c}\text { Job stress } \\
\text { x Growth } \\
\text { mindset }\end{array}$ & -.1509 & .0765 & -1.9739 & .0492 & -.3014 & -.0005 \\
\hline \multicolumn{7}{|c|}{ Test of highest order unconditional interaction } \\
\hline & & \multicolumn{2}{|l|}{$R^{2}$} & $\mathrm{~F}$ & \multicolumn{2}{|c|}{$\mathrm{p}$} \\
\hline \multicolumn{2}{|c|}{$\begin{array}{c}\text { Job stress x Growth } \\
\text { mindset }\end{array}$} & \multicolumn{2}{|c|}{.0104} & 3.8963 & \multicolumn{2}{|c|}{.0492} \\
\hline \multicolumn{7}{|c|}{ Conditional effects of the job stress at values of growth mindset } \\
\hline $\begin{array}{l}\text { Growth } \\
\text { mindset }\end{array}$ & Effect & se & $\mathrm{t}$ & $\mathrm{p}$ & $\mathrm{LLCI}^{*}$ & $\mathrm{ULCI}^{* *}$ \\
\hline-.6128 & -.1099 & .0673 & -.1 .6314 & .1038 & -.2423 & .0266 \\
\hline .0000 & -.2024 & .0516 & -3.9243 & .0001 & -.3038 & -.1009 \\
\hline .6128 & -.2949 & .0719 & -4.0986 & .0001 & -.4364 & -.1533 \\
\hline
\end{tabular}

Conditional effects of the job stress at values of growth mindset

\begin{tabular}{|c|c|c|c|c|c|c|}
\hline $\begin{array}{c}\text { Growth } \\
\text { mindset }\end{array}$ & Effect & $\mathrm{se}$ & $\mathrm{t}$ & $\mathrm{p}$ & LLCI & ULCI \\
\hline-1.7131 & .0562 & .1376 & .4086 & .6831 & -.2144 & .3268 \\
\hline
\end{tabular}

\begin{tabular}{|c|c|c|c|c|c|c|}
\hline-.5318 & -.1221 & .0635 & -1.9220 & .0555 & -.2470 & .0029 \\
\hline $\mathbf{- . 5 1 9 8}$ & $\mathbf{- . 1 2 3 9}$ & $\mathbf{. 0 6 3 0}$ & $\mathbf{- 1 . 9 6 7 1}$ & $\mathbf{. 0 5 0 0}$ & $\mathbf{- . 2 4 7 8}$ & $\mathbf{. 0 0 0 0}$ \\
\hline-.3631 & -.1476 & .0569 & -2.5923 & .0100 & -.2595 & -.0356 \\
\hline
\end{tabular}

\begin{tabular}{|c|c|c|c|c|c|c|}
\hline 1.6619 & -.4532 & .1403 & -3.2308 & .0014 & -.7291 & -.1773 \\
\hline \multicolumn{7}{|c|}{ Dependent variable model (DV: Happiness) } \\
\hline Variables & Effect & SE & t-value & $\mathrm{p}$ & LLCI $^{*}$ & ULCI $^{* *}$ \\
\hline Constant & 1.6686 & .1784 & 9.3528 & .0000 & 1.3177 & 2.0196 \\
\hline Job stress & -.2490 & .0478 & -5.2107 & .0000 & -.3430 & -.1550 \\
\hline Hope & .5741 & .0495 & 11.6068 & .0000 & .4768 & .6714 \\
\hline
\end{tabular}

Conditional indirect effects of $\mathrm{X}$ on $\mathrm{Y}($ Job stress $\rightarrow$ Hope $\rightarrow$ Happiness $)$

\begin{tabular}{|c|c|c|c|c|}
\hline $\begin{array}{c}\text { Growth } \\
\text { mindset }\end{array}$ & Effect & Bootse & LLCI $^{*}$ & ULCI $^{* *}$ \\
\hline-.6128 & -.0631 & .0535 & -.1670 & .0459 \\
\hline $\mathbf{. 0 0 0 0}$ & $\mathbf{- . 1 1 6 2}$ & $\mathbf{. 0 3 9 8}$ & $\mathbf{- . 1 9 6 4}$ & $\mathbf{- . 0 3 9 7}$ \\
\hline $\mathbf{. 6 1 2 8}$ & $\mathbf{- . 1 6 9 3}$ & $\mathbf{. 0 5 5 2}$ & $\mathbf{- . 2 7 9 1}$ & $\mathbf{- . 0 6 3 4}$ \\
\hline
\end{tabular}

$*$ LLCI $=$ boot lower limit value within the $95 \%$ confidence interval of the indirect effect

$* * \mathrm{ULCI}=$ boot upper limit value within the $95 \%$ confidence interval of the indirect effect

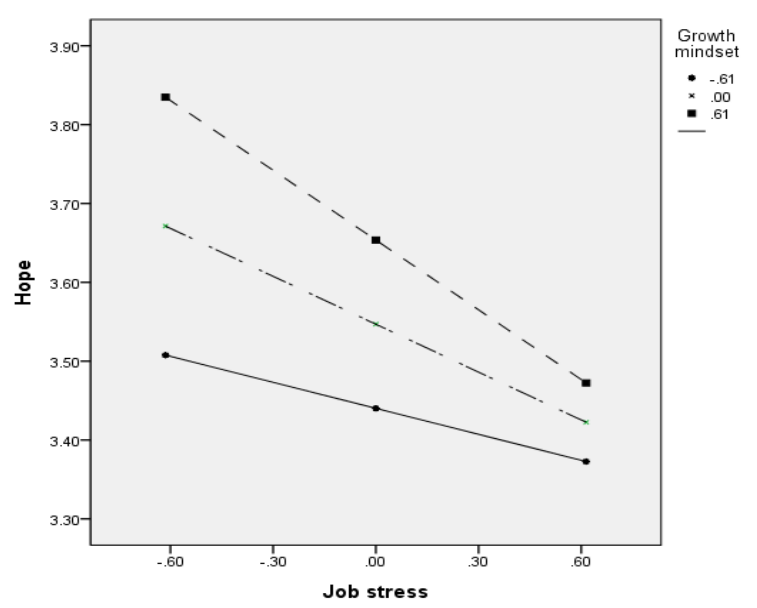

Figure 2. The moderating effect of growth mindset on the relationship between job stress and hope

\section{CONCLUSION}

This study analyzed whether the growth mindset of the workers moderates the path from happiness to hope through the incidence or presence of job stress. First, job stress had a negative correlation with the perception of employee based hopes, a growth mindset and happiness. Second, as a result of the moderated mediation effect analysis, the conditional indirect effect of growth mindset was verified, which tested the moderated mediation effect of a growth mindset. Based on these results, further researches were suggested as follows.

First, in this study, we did not verify the difference of major variables according to the possible available demographic characteristics. Future studies need to analyze these differences and identify the reasons for the differences utilizing research data. Second, this study did not analyze any differences in the consideration of various types of workers. This being noted, that correlations, mediating effects, moderating effects and moderated mediating effects are expected to be different depending on various types of workers, and further studies are needed to review those results. Third, further researches are needed to develop specific programs by using the ideas of a hope and growth mindset, such as to include mediation and moderation variables in order to enhance the happiness of workers.

\section{ACKNOWLEDGMENT}

This paper was undertaken with the support of a research grant in 2019 from the Hanseo University.

\section{REFERENCES}

1. D. C. Shin, D. M. Johnson. "Avowed happiness as an overall assessment of the quality of life." Social Indicators Research, 5(1-4), 475-492, 1978.

2. E. Diener. "Subjective well-being." Psychological Bulletin, 95(3), 542-575, 1984.

3. R. Veenhoven. "Is happiness relative?" Social Indicators Research, 24(1), 1-34, 1991.

4. D. L. Rogers. "Sociometric analysis of interorganizational relations: application of theory and measurement." Rural Sociology, 39(4), 487, 1974. 
5. S. M. Jex. Stress and job performance: Theory, research, and implications for managerial practice. Thousand Oaks: Sage Publications Ltd, 1998.

6. G. Blau. "An empirical investigation of job stress, social support, service length, and job strain." Organizational Behavior and Human Performance, 27(2), 279-302,1981.

7. K. J. Harris, M. James, R. Boonthanom. "Perceptions of organizational politics and cooperation as moderators of the relationship between job strains and intent to turnover." Journal of Managerial Issues, 17(1), 26-42, 2005

8. E. Demerouti, A. B. Bakker, J. De Jonge, P. P. Janssen, W. B. Schaufeli. "Burnout and engagement at work as a function of demands and control." Scandinavian Journal of Work, Environment \& Health, 27(4), 279-286, 2001.

9. S. M. Jex, P. D. Bliese, S. Buzzell, J. Primeau. "The impact of self-efficacy on stressor-strain relations: coping style as an explanatory mechanism." Journal of Applied Psychology, 86(3), 401-409, 2001

10. C. L. Cooper, J. Marshall. "Occupational sources of stress: a review of the literature relating to coronary heart disease and mental ill health." Journal of Occupational Psychology, 49(1), 11-28, 1976.

11. N. Gupta, T. A. Beehr. "Job stress and employee behaviors." Organizational behavior and human performance, 23(3), 373-387, 1979.

12. R. S. Schuler. "Definition and conceptualization of stress in organizations." Organizational Behavior and Human Performance, 25(2), 184-215, 1980. DOI:10.1016/0030-5073(80)90063-X

13. D. F. Parker, T. A. DeCotiis. "Organizational determinants of job stress." Organizational Behavior and Human Performance, 32(2), 160-177, 1983. DOI:10.1016/0030-5073(83)90145-9

14. O. N. Joo, S. Y. Moon. "The mediation effect of mental health on the relationship between job stress and happiness of social workers in mental health facilities." Mental Health and Social Work, 42(1), 114-143, 2014.

15. S. K. Lee, M. H. Lee, K. E. Kim. "Effects of early childhood teachers' job stress on happiness and organizational commitment." Journal of Children's Literature and Education, 15(4), 661-680, 2014.

16. Y. H. Kwon. "The effects of organizational climate and self-esteem on teachers' job stress in corporate-sponsored child care centers." The Journal of Korea Open Association for Early Childhood Education, 15(5), 437-455, 2010

17. E. H. Jang. "The effect of the job stress of local government employees on the job involvement: with focus on the moderating effect of the subjective well-being and the family strengths." Master's Thesis, Yonsei University, 2012.

18. E. S. Lee, K. N. Lee. "Influence of emotional intelligence on happiness in infant and toddler teachers: mediating effect of job stress and teacher efficacy." Korean Journal of Childcare and Education, 11(2), 221-238, 2015.

19. K. Menninger. "The academic lecture: Hope." American Journal of Psychiatry, 116(6), 481-491, 1959.

20. E. Stotland. The psychology of hope. Jossey-Bass, 1969.

21. C. R. Snyder, Forsyth, R. Donelson. Handbook of social and clinical psychology: the health perspective. New York: Pergamon Press, 1991.

22. C. R. Snyder, C. Harris, J. R. Anderson, S. A. Holleran, L. M. Irving, S. T. Sigmon, et al. "The will and the ways: development and validation of an individual-differences measure of hope." Journal of Personality and Social Psychology, 60(4), 570-655, 1991.

23. C. R. Snyder. "Hope theory: rainbows in the mind." Psychological Inquiry, 13(4), 249-275, 2002.

24. C. R. Snyder. The psychology of hope: you can get there from here. New York: Free press, 1994.

25. C. R. Snyder. "The past and possible futures of hope.” Journal of Social and Clinical Psychology. 19(1), 11-28, 2000.

26. C. R. Snyder, L. Kelvin. Hope theory. In C. R. Snyder, J. S. Lopez (Eds.), Handbook of positive psychology, 2002.

27. V. H. Adams, C. R. Snyder, K. L. Rand, E. A. King, D. R. Sigmon, K. M. Pulvers. Hope in the workplace. Handbook of Workplace Spirituality and Organizational Performance, 2002

28. A. D. Ong, L. M. Edwards, C. S. Bergeman. "Hope as a source of resilience in later adulthood." Personality and Individual Differences, 41(7), 1263-1273, 2006.

29. C. S. Lee, J. Y. Park. "The effects of acculturative and family-related stress on the well-being of immigrant women in korea: the mediating effect of hope." Indian Journal of Science and Technology, 9(26), 1-7, 2016

30. J. Y. Park, C. S. Lee. "Mediating effect of hope between stress coping and psychological wellbeing of women immigrants." Journal of Digital Convergence, 11(1), 405-412, 2013.
31. C. S. Lee, S. U. Park, Y. K. Hwang. "The structural relationship between mother's parenting stress and child's well-being: the mediating effects of mother's growth mindset and hope." Indian Journal of Science and Technology, 9(36), 1-6, 2016.

32. H. S. Shorey, C. R. Snyder, X. Yang, M. R. Lewin. "The role of hope as a mediator in recollected parenting, adult attachment, and mental health." Journal of Social and Clinical Psychology, 22(6), 685-715, 2003.

33. C. S. Dweck. Mindset: The new psychology of success. Random House Digital, Inc., 2008.

34. C. S. Dweck. "Caution-Praise can be dangerous." American Educator, 23(1), 4-9, 1999.

35. A. Hochanadel, D. Finamore. "Fixed and growth mindset in education and how grit helps students persist in the face of adversity." Journal of International Education Research, 11(1), 47-50, 2015.

36. C. S. Dweck, C. Y. Chiu, Y. Y. Hong. "Implicit theories and their role in judgments and reactions: a word from two perspectives." Psychological Inquiry, 6(4), 267-285, 1995.

37. C. S. Dweck, A. Master. Self-theories and motivation: students' beliefs about intelligence. In K. R. Wentzel, A. Wigfield. (Eds.), Handbook of Motivation at School. Routledge, 2009.

38. A. J. Crum, P. Salovey, S. Achor. "Rethinking stress: The role of mindsets in determining the stress response.” Journal of Personality and Social Psychology, 104(4), 716, 2013.

39. C. S. Lee. "Authentic leadership and organizational effectiveness: the roles of hope, grit, and growth mindset." International Journal of Pure and Applied Mathematics, 118(19), 383-401, 2018.

40. C. S. Lee, M. N. Jung, G. H. Lee. "The moderated effect of growth mindset on the relationship between authentic leadership and organizational effectiveness." International Journal of Pure and Applied Mathematics, 118(19), 415-426, 2018.

41. Y. K. Hwang, C. S. Lee. "Relationship between Stress and Happiness in Middle School Students: dual mediation effect of growth mindset and self-esteem." Medico-Legal Update, 18(1), 248-253, 2018.

42. Samsung. Economic Research Institute. Samsung Economics, 2010.

43. D. H. Lee. "The experience of stress among Korean employees working in a large conglomerate." Master's Thesis, Inha University, 2013.

44. M. S. Ha, Y. S. Kwon. "A study of antecedents and consequences of job stress in the Korean public sector." The Korean Journal of Public Administration, 11(3), 214-245, 2002.

45. Y. H. Choi, H. K. Lee, D. G. Lee. "Validation of the Korean version of Snyder's dispositional hope scale." Korean Journal of Social and Personality Psychology, 22(2), 1-16, 2008.

46. S. Lyubomirsky, H. S. Lepper. "A measure of subjective happiness: preliminary reliability and construct validation." Social Indicators Research, 46(2), 137-155, 1999.

47. J. W. Shin. "Effect of working women's work/family conflict, emotional intelligence, and emotional labor on happiness." Master's Thesis, Chung Buk University, 2012.

48. A. F. Hayes. Introduction to mediation, moderation, and conditional process analysis: a regression based approach. New York: The Guilford Press, 2018

\section{AUTHORS PROFILE}

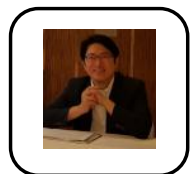

Chang Seek Lee received Bachelor's and Master's degree in lifelong education from Seoul National University in Korea and Ph.D. in lifelong education from University of the Philippines in the Philippines in 1991. $\mathrm{He}$ is chairman of health, counseling and welfare department of Hanseo University, South Korea and Head of Multicultural Education and Welfare Institute of Hanseo University. His primary research interests are program development, lifelong education and multicultural education.

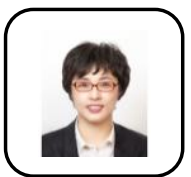

Ji Young Park received Bachelor's degree in literature from Chonnam National University in 1992, Master's degree in tea science from Hanseo University in 2005 and Doctor of Social Welfare from Hanseo University in Korea in 2011. She is Professor of Child and Elderly Welfare department, Koguryo University. Her primary research interests are multiculturalism, and welfare for the elderly.. 